\title{
Periungual Pyogenic Granuloma-Like Lesions During Isotretinoin Treatment for Acne: Two Case Reports and a Literature Review
}

\author{
Predrag ŠTILET ${ }^{1}$, Miloš D. PAVLOVIĆ 2 \\ ${ }^{1}$ Dermatology Outpatient Clinic "Dr Štilet”, Podgorica, Montenegro \\ ${ }^{2}$ Parmova Dermatology Center, Ljubljana \& School of Medicine, University of Maribor, Maribor, Slovenia \\ ${ }^{*}$ Correspondence: Miloš D. Pavlović, E mail: milos.pavlovic@dcp.si \\ UDK 616.53-002-08:615.262.06 \\ DE GRUYTER
OPEN
}

\begin{abstract}
Periungual pyogenic granuloma-like lesions are not uncommon side effects of isotretinoin therapy, but these cases are relatively infrequently reported. Excessive granulation tissue appeared in two patients receiving oral isotretinoin therapy for severe acne. Once isotretinoin was discontinued, the outgrowths resolved spontaneously in both patients. It is probably an idiosyncratic reaction to isotretinoin which renders the skin more susceptible to extracellular matrix and blood vessel formation. Moreover, similar lesions may be observed particularly with newer targeted therapies, such as inhibitors of epidermal growth factor receptor (EGFR) and mitogen-activated protein kinase kinases (MEKs). EGFR inhibitors associated painful periungual inflammation (paronychia), which often arises from the nail wall during newer targeted therapies, has been classified in the third major group of dermatologic toxicity. Cutaneous toxicity may be interpreted as a stress response that affects epidermal homeostasis. In the cell, stress signals are transmitted to effectors which then produce an inflammatory response.

In conclusion, paronychia and excessive granulation tissue in the nail folds are not uncommon side effects of oral retinoids. It is therefore particularly important for practicing dermatologists to be aware that the best management approach is drug discontinuation.
\end{abstract}

\section{Key words}

Granuloma, Pyogenic; Nail Diseases; Isotretinoin + adverse effects; Acne Vulgaris; Case Reports; Review

sotretinoin (13-cis retinoic acid) is a well established
and the most effective treatment for severe acne, or acne non-responsive to other treatment options. Primarily due to its teratogenic effects, the use of isotretinoin has been strictly regulated and supervised in women of childbearing age, but many other side effects have been well documented. As early as in 1983, the first reports on excess granulation tissue resembling pyogenic granuloma within resolving acne lesions and around nails, were published in patients treated with oral isotretinoin for acne and with etretinate for psoriasis, respectively $(1,2)$. Although these side effects are probably not so rare, there are very few reports published in the world literature describing their clinical course and treatment modalities.
Here we report on two men treated with oral isotretinoin for severe acne who developed paronychia and periungual pyogenic granuloma-like lesions.

\section{Case reports}

Case 1

An otherwise healthy 18-year-old male received isotretinoin therapy for severe facial acne at a dosage of $60 \mathrm{mg}$ per day $(0.7 \mathrm{mg} / \mathrm{kg})$. After two months of therapy, he noticed lesions on his fingers. On examination, he presented with painful erythema and slight edema on the periungual skin on several fingers with painful and eroded excessive granulation tissue over the nail folds on the left third, and right fourth finger (Figures 1 and 2). Antiseptic lotions 


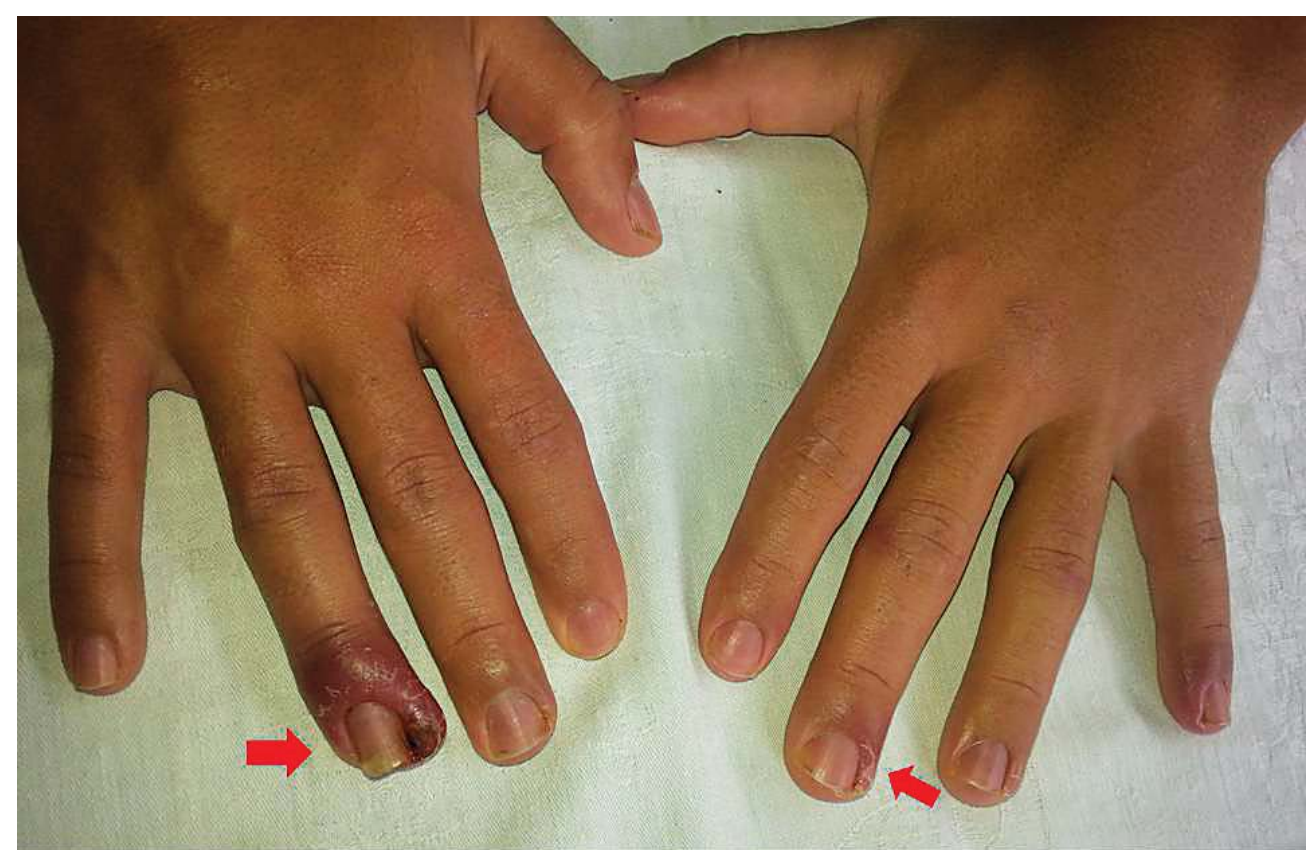

Figure 1. Excess periungual granulation tissue and paronychia on figers of both hands (arrows).

and antibiotic ointment were ineffective. He stopped taking isotretinoin, and all lesions disappeared within 3 weeks.

\section{Case 2.}

A 19-year-old male with severe nodular acne on the face and upper back received isotretinoin at a dose of $80 \mathrm{mg}$ daily $(0.9 \mathrm{mg} / \mathrm{kg})$. Six weeks after the beginning of treatment, he developed painful paronychia of all fingers with several pyogenic granuloma-like nodules on lateral nail folds. The isotretinoin dosage was reduced to $60 \mathrm{mg}$ daily without benefit, so two weeks later he quit the drug, and all lesions regressed within 2 weeks.

\section{Discussion}

Inflammation of the periungual tissue progressing to painful and bleeding pyogenic granuloma-like lesions is a well-known side effect of some drugs, like oral and topical retinoids $(3-7)$. Paronychia is an infection of the distal and lateral nail folds, with associated excess granulation tissue. Usually multiple fingers and/ or toes, rarely all, are involved, and in some patients rechallenge with isotretinoin leads to a secondary flare-up, suggesting causality. A recent retrospective study of 1.743 patients treated with oral isotretinoin, showed "periungual granuloma" in $2.1 \%$ of subjects (8). Similar lesions may be observed particularly with newer targeted therapies $(9-11)$, like epidermal growth factor receptor (EGFR) inhibitors $(9,12)$ and mitogenactivated protein kinase kinases (MEKs) (13).

A number of new cancer drugs have recently been approved. Contrary to conventional chemotherapy, EGFR inhibitors have low hematotoxicity. Their side effects profile is distinct from older antitumor drugs, especially with regard to the skin. Regarding classification of their adverse cutaneous effects, EGFR inhibitors associated painful periungual inflammation (paronychia), that often arises from the nail wall and is associated with abundant formation of granulation tissue, has been classified in the third major group of cutaneous toxicity (9). Cutaneous toxicity may be interpreted as a stress response that affects epidermal homeostasis. Stress signals are transmitted to effectors in the cells which may produce an inflammatory response (9). MEK inhibitors inhibit the same signaling pathways as the EGFR inhibitors. It is well known that kinases play an important role in many intracellular signaling pathways, including those that control cell growth and cell division, such as mitogen-activated protein kinases (MAPKs). The kinases that phosphorylate and activate MAPKs, are known as MAP kinase kinases (MEKs). 


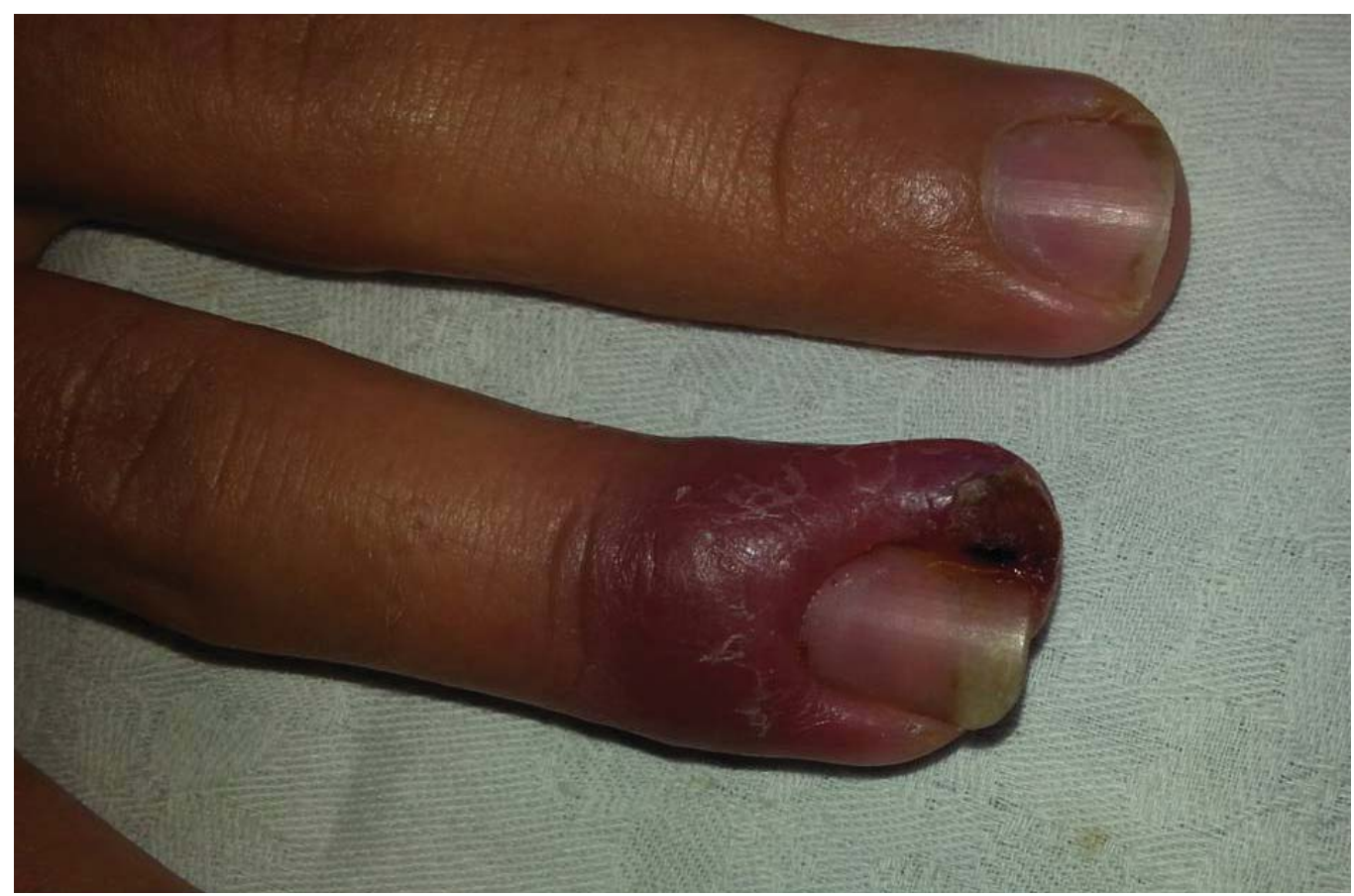

Figure 2. The lesion on the right fourth digit showing massively swollen periungual tissue, erythema, and erosion with maceration

Because EGFR signals downstream also through MEK signaling pathway, it can be expected that MEK inhibitors therefore cause similar cutaneous adverse events as EGFR inhibitors. Indeed, there was clinically a biphasic cutaneous side effect profile as was also reported for EGFR inhibition (13). A papulopustular rash in the seborrhoeic area was observed in acute phase, while xerosis cutis, fissured finger tips or paronychia with abundant formation of granulation tissue developed in the late phase. The histology of these lesions revealed that MEK inhibition mainly targeted the basal keratinocytes, since they are normally characterized by high EGFR expression; the reduced basal cell proliferation was compensated by increased suprabasal proliferation produced by self-amplifying cells within the suprabasal layer (13).

The lesions in acne patients treated with isotretinoin have not been biopsied, so we have to infer about their histopathologic features from similar lesions induced by other drugs which were sampled, e.g. inhibitor of EGFR (gefitinib). The lesions showed marked inflammation and numerous and prominent vessels in the dermis infiltrated with inflammatory cells consisting mostly of plasma cells, lymphocytes, and some neutrophils (12).
We can only speculate about the pathogenesis of retinoid-induced periungual excessive granulation tissue. Retinoids are known to promote wound healing in the early stages, accumulation of mononuclear cells in the dermis, and stimulate collagen synthesis. These factors may increase the patient's susceptibility to overgrowth of new granulation tissue (2). Isotretinoin affects expression of many genes, such as those known to encode extracellular matrix proteins which are therefore consistently upregulated (14). Although an increase in extracellular matrix may be consistent with theappearance of outgrowths, animal model studies have shown that 13-cis retinoic acid actually inhibits angiogenesis through inhibition of endothelial cell migration, tube formation, and altered cytokine production during the onset of angiogenesis (15). However, in other biologic systems, as in spermatogenesis, it was shown that signaling pathways induced by retinoic acid and MEK pathway are mutually exclusive (16), indicating that isotretinoin and MEK inhibitors may cause similar side effects.

Multiple therapeutic options of cutaneous side effects have been used, but few showed any consistent benefits (1-7). A two-week course of a potent topical 
corticosteroid under occlusion and topical antibiotics have been suggested as first-line treatments for periungual pyogenic granulomas (4). Nevertheless, drug-induced pyogenic granuloma-like lesions resolved after withdrawal of the causal agent and reappeared on rechallenge $(9,13)$. Thus, in our case, withdrawal of isotretinoin was followed by complete and rapid resolution in both patients.

\section{Conclusion}

In conclusion, paronychia and excessive granulation tissue in the nail folds are not uncommon side effects of oral retinoids. It is therefore particularly important for practicing dermatologists to be aware that the best management approach is drug discontinuation.

\section{Abbreviations}

EGFR - growth factor receptor

MEKs - mitogen-activated protein kinase kinases

MAP2Ks - mitogen-activated protein kinases

\section{References:}

1. Exner JH, Dahod S, Pochi PE. Pyogenic granuloma-like acne lesions during isotretinoin therapy. Arch Dermatol 1983;119:808-11.

2. Campbell JP, Grekin RC, Ellis CN, Matsuda-John SS, Swanson NA, Voorhees JJ. Retinoid therapy is associated with excess granulation tissue responses. J Am Acad Dermatol 1983;9:708-13.

3. Bigby M, Stern RS. Adverse reactions to isotretinoin. A report from the Adverse Drug Reaction Reporting System. J Am Acad Dermatol 1988;18:543-52.

4. Piraccini BM, Bellavista S, Misciali C, Tosti A, de Berker D, Richert B. Periungual and subungual pyogenic granuloma. Br J Dermatol 2010;163:941-53.
5. Armstrong K, Weinstein M. Pyogenic granulomas during isotretinoin therapy. J Dermatol Case Rep 2011;5:5-7.

6. Blumental G. Paronychia and pyogenic granuloma-like lesions with isotretinoin. J Am Acad Dermatol 1984;10:677-8.

7. MacKenzie-Wood AR, Wood G. Pyogenic granulomalike lesions in a patient using topical tretinoin. Australas J Dermatol 1998;39:248-50.

8. Rademaker M. Adverse effects of isotretinoin: A retrospective review of 1743 patients started on isotretinoin. Australas J Dermatol 2010;51:248-53.

9. Gutzmer R, Wollenberg A, Ugurel S, Homey B, Ganser A, Kapp A. Cutaneous side effects of new antitumor drugs. Clinical features and management. Dtsch Arztebl Int 2012;109(8):133-40.

10. Macdonald JB, Macdonald B, Golitz LE, LoRusso P, Sekulic A. Cutaneous adverse effects of targeted therapies: Part I: Inhibitors of the cellular membrane. J Am Acad Dermatol 2015;72:203-18.

11. Macdonald JB, Macdonald B, Golitz LE, LoRusso P, Sekulic A. Cutaneous adverse effects of targeted therapies: Part II: Inhibitors of intracellular molecular signaling pathways. J Am Acad Dermatol 2015;72:221-36.

12.Chang GC, Yang TY, Chen KC, Yin MC, Wang RC, Lin YC. Complications of therapy in cancer patients: Case 1. Paronychia and skin hyperpigmentation induced by gefitinib in advanced non-small-cell lung cancer. J Clin Oncol 2004;22:4646-8.

13.Schad K, Baumann Conzett K, Zipser MC, Enderlin V, Kamarashev J, French LE, et al. Mitogen-activated protein/ extracellular signal-regulated kinase kinase inhibition results in biphasic alteration of epidermal homeostasis with keratinocytic apoptosis and pigmentation disorders. Clin Cancer Res 2010;16:1058-64.

14. Nelson AM, Zhao W, Gilliland KL, Zaenglein AL, Liu W, Thiboutot DM. Temporal changes in gene expression in the skin of patients treated with isotretinoin provide insight into its mechanism of action. Dermatoendocrinol 2009;1:177-87.

15.Guruvayoorappan C, Kuttan G. 13 cis-retinoic acid regulates cytokine production and inhibits angiogenesis by disrupting endothelial cell migration and tube formation. J Exp Ther Oncol 2008;7:173-82.

16. Hasegawa K, Namekawa SH, Saga Y. MEK/ERK signaling directly and indirectly contributes to the cyclical self-renewal of spermatogonial stem cells. Stem Cells 2013;31:2517-27.

\section{Periungvalni izraštaji slični piogenom granulomu tokom lečenja akni izotretinoinom - prikaz dva slučaja i pregled literature}

\section{Sažetak}

Uvod. Periungvalni izraštaji slični piogenom granulomu nisu tako redak neželjeni efekat tokom lečenja izotretinoinom ali su do sada veoma retko opisivani u literaturi. U pitanju je najverovatnije idiosinkrazijska reakcija kod koje izotretinoin „priprema“ kožu pošto značajno utiče na sintezu komponenti vanćelijskog matriksa i rast novih krvnih sudova. Prvi slučajevi ekstenzivnog periungvalnog rasta granulacionog tkiva nalik na piogeni granulom tokom terapije retinoidima, koji su objavljeni u svetskoj literaturi 1983. godine, odnosili su se na izotretinoin tokom lečenja akni i etretinat u toku lečenja psorijaze.

Prikaz slučaja. U ovom radu prikazujemo dva naša 
mlada pacijenta lečena oralnim izotretinoinom zbog teških akni, kod kojih je došlo do preteranog rasta periungvalnog granulacionog tkiva. Kod oba mladića su se promene spontano povukle posle prekida uzimanja leka.

Slučaj 1. Inače zdrav, 18 godina star mladić, lečen je zbog teškog oblika akni na licu izotretinoinom u dnevnoj dozi od $60 \mathrm{mg}(0,7 \mathrm{mg} / \mathrm{kg} T \mathrm{~T})$. Dva meseca posle započinjanja terapije, primetio je prve promene na prstima ruku (slike 1 i 2). Antiseptički losioni i antibiotske masti aplikovani su lokalno, ali nije bilo poboljšanja. Do potpune regresije svih promena došlo je u toku tri sledeće nedelje, pošto je izotretinoin u potpunosti obustavljen. Slučaj 2. Mladić star 19 godina sa teškim oblikom nodularnih akni na licu i leđima, inače zdrav, lečen je izotretinoinom u dnevnoj dozi od $80 \mathrm{mg}(0,9 \mathrm{mg} / \mathrm{kgTT})$. Šest nedelja nakon započinjanja lečenja, na svim prstima ruku, došlo je do pojave bolne paronihije a na lateralnim nokatnim naborima na pojedinim prstima razvili su se nodulusi slični piogenom granulomu. Doza izotretinoina je smanjena na $60 \mathrm{mg}$ dnevno bez vidljivog efekta. Do potpune regresije svih promena došlo je u toku dve sledeće nedelje, pošto je izotretinoin u potpunosti obustavljen.

Diskusija. Inflamacija periungvalnog tkiva sa progresijom u bolne, krvavljenju sklone lezije nalik na piogeni granulom, dobro je poznati neželjeni efekat tokom primene pojedinih lekova, npr. sistemskih i lokalnih retinoida. U paronihiji dolazi do bujanja lateralnih i distalnih nokatnih nabora sa ekstremnim stvaranjem granulacionog tkiva. Obično je oboljenjem zahvaćen veći broj prstiju na nogama i na rukama, ređe svi. U onim slučajevima u kojima je pacijentima ponovo u terapiju uvođen izotretinoin, došlo je do sekundarnog recidiva, što ukazuje na kauzalnu vezu. Rezultati retrospektivne studije, koja je sprovedena na 1743 pacijenta, pokazali su da je periungualni granulom imalo $2,1 \%$ svih izotretinoinom lečenih osoba. Identične promene mogu biti neželjeni efekti nove ciljane biološke terapije, npr. u toku primene inhibitora EGFR (eng. epidermal growth factor receptor) i inhibitora onih kinaza koje aktivišu mitogen-aktivisane kinaze - MEKs (eng. mitogen activated kinase kinases).

Veliki broj novih lekova sa antitumorskim ciljanim delovanjem nedavno je odobren. Za razliku od konvencionalne hemoterapije, lečenje ciljanim antitumorskim lekovima nove generacije povezano je sa manjim stepenom hematotoksičnosti. Neželjeni efekti terapije ovim lekovima se razlikuju od spektra klasičnih antitumorskih agenasa, naročito kada je profil neželjenih kutanih efekata u pitanju. Neželjeni kutani efekti su kategorisani u zavisnosti od težine i vremena njihovog javljanja u tri kategorije kutane toksičnosti. Neželjeni efekati u toku terapije inhibitorima EGFR, koje čine bolne paronihije sa ekscesivnim bujanjem granulacionog tkiva, ulaze u treću grupu kutane toksičnosti. Kutana toksičnost se može identifikovati sa odgovorom na stres koji narušava epidermalnu homeostazu. Stresni signali se u ćeliji prenose na efektore koji potom produkuju inflamatorni odgovor. Jedan isti signal može biti inhibisan i sa EGFR inhibitorima i sa MEK inhibitorima. Poznat je značaj koji kinaze, npr. MAPKs (eng. mitogen activated kinases), imaju u sistemima koji kontrolišu mnoge ključne intraćelijske procese kao što je kontrola rasta i deoba ćelije; MAPKs bivaju aktivisane fosforilacijom od strane MEKs. S obzirom da EGFR signali prolaze i kroz MEK signalne puteve, može se očekivati da njihovi inhibitori ispoljavaju ista neželjena dejstva na kožu. Rezultati ispitivanja koja su usledila potvrdili su ovu pretpostavku; u toku terapije MEK inhibitorima javio se bifazni kutani neželjeni profil koji se na isti način javio $\mathrm{u}$ toku terapije EGFR inhibitorima. U akutnoj fazi papulopustulozni osip izražen naročito u seboroičnim regijama, a kseroza kože, fisure na jagodicama prstiju ili paronihija s ekcesivnim bujanjem periungvalnog granulacionog tkiva u hroničnoj fazi (posle 6 nedelja).

O patogenezi bujanja ekscezivnog granulacijskog tkiva u toku terapijske primene retinoida, možemo samo spekulisati na osnovu njihovih dobro poznatih osobina na osnovu kojih mogu povećati prijemčivost za ekscesivno bujanje granulacionog tkiva: promovišu proces zarastanja rana u početnoj fazi; dovode do akumulacije mononuklearnih ćelija u dermis; stimulišu produkciju kolagena. Izotretinoin utiče na ekspresiju mnogih gena, npr. gena koji kodiraju sintezu ekstraćelijskih matriksnih proteina. Dok povećanje sinteze ekstraćelijskih matriksnih proteina može objasniti ulogu retinoida u bujanju granulacijskog tkiva, u eksperimentima na životinjama, utvrđeno je da 13-cis retinoična kiselina inhibiše angiogenezu putem inhibicije migracije endotelnih ćelija, 
formiranja cevi i produkcije citokina. Bez obzira na ove kontroverze, u drugim biološkim sistemima, npr. spermatogenezi, pokazano je su mehanizmi delovanja retinoida i MEKs isključivi, što ukazuje na mogućnost da izotretinoin i MEKs inhibitori mogu proizvesti iste neželjene kutane efekte.

Mnogi terapijski modaliteti isprobani su sa ciljem kupiranja navedenih neželjenih kutanih efekata, ali bez željenog efekta. Potpuno ukidanje inkriminisanog leka, u našem slučaju izotretinoina dovodi do potpune sanacije lezija, a u slučajevima u kojima je izotretinoin ponovo uvođen u terapiju, dolazilo je do ponovnog recidiva periungvalnih lezija, što ukazuje na njihovu uzročno-posledičnu povazanost.

Zaključak. Prikazom dva slučaja periungvalnih izraštaja sličnih piogenom granulomu ističemo da svaki dermatolog treba da zna da oni nisu tako redak neželjeni efekat tokom lečenja izotretinoinom; jedino prestanak uzimanja leka može dovesti do njihove sanacije i to u kratkom vremenskom periodu.

\section{Ključne reči}

Piogeni granulom; Bolesti noktiju; Izotretinoin + neželjena dejstva; Acne vulgaris; Prikazi slučajeva; Pregled literature 